\title{
Coinfecciones bacterianas causantes de enfermedad diarreica aguda, en el Instituto Nacional de Salud del Niño
}

\author{
Bacterial coinfections causing acute diarrhea, at the Instituto Nacional \\ de Salud del Niño
}

\author{
Edgar Gonzales Escalante $e^{1,2, a, b}$ \\ ${ }^{1}$ Instituto Nacional De Salud Del Niño, Lima, Perú. \\ ${ }^{2}$ Laboratorio de Epidemiologia Molecular y Genética, Instituto de Medicina Tropical, Universidad Nacional Mayor de San Marcos, Lima, \\ Perú. \\ ${ }^{a}$ Tecnólogo Médico; ${ }^{b}$ Magister en Microbiología.
}

\section{An Fac med. 2015;76(4):463-4 / http://dx.doi.org/10.15381/anales.v76i4.11420}

\section{SR. EDITOR:}

En pleno siglo XXI, las enfermedades diarreicas continúan representando un importante problema de salud pública. Según los registros de la Organización Mundial de la Salud (OMS), en los países en desarrollo los niños menores de 5 años experimentan un promedio de 3,2 episodios de diarrea anualmente ${ }^{(1,2)}$.

La enfermedad diarreica aguda (EDA), principalmente infecciosa, constituye un problema de salud pública en el Perú debido a su alto costo económico, social y familiar; siendo una de las principales causas de morbilidad y mortalidad en la niñez ${ }^{(3)}$.

Algunos de los patógenos bacterianos más importantes observados en el mundo incluyen Aeromonas spp., Campylobacter spp., Escherichia coli diarreogénica, Salmonella spp., Shigella spp., Vibrio cholerae y Yersinia spp ${ }^{(4)}$. En general las infecciones bacterianas causantes de EDA son monomicrobianas, es decir, producidas por un solo germen, pero en algunas ocasiones estas pueden ser causadas por dos o hasta tres bacterias ${ }^{(5,6)}$.
En el Instituto Nacional de Salud del Niño, las muestras de heces con solicitud de coprocultivo son sembradas en los medios selectivos agar Mac Conkey Sorbitol, agar XLD, agar TCBS, agar SS, medio selectivo para Campylobacter (agar sangre con suplemento Butzler) y medio de enriquecimiento caldo Selenito, que después de 18 horas es resembrado en agar SS. Luego, con las colonias sospechosas se hace la identificación presuntiva por pruebas de bioquímica convencional

Tabla 1. Bacterias enteropatogenas aisladas entre enero de 2010 y abril de 2015.

\begin{tabular}{ccc} 
Microorganismos & $\begin{array}{c}\mathrm{N}^{0} \\
\text { aislamientos }\end{array}$ & $\%$ \\
Campylobacter $s p$. & 831 & 44,5 \\
Shigella sp. & 667 & 35,7 \\
Salmonella $s p$. & 257 & 13,8 \\
Aeromonas sp. & 74 & 4,0 \\
Plesiomonas shigelloides & 32 & 1,7 \\
Yersinia enterocolitica & 3 & 0,2 \\
Vibrio cholerae & 2 & 0,1 \\
Vibrio parahaemolyticus & 1 & 0,1 \\
\hline Total & 1867 & 100,0 \\
\hline
\end{tabular}

y la confirmación por serología en los casos que lo amerite; finalmente se realizan las pruebas de susceptibilidad.

Entre enero de 2010 y abril de 2015 se aislaron un total de 1867 bacterias enteropatógenas, siendo los gérmenes más frecuentemente aislados Campylobacter sp. y Shigella sp. Los aislamientos de recuperados se detallan en la tabla 1.

De estos aislamientos se pudo evidenciar que algunos pertenecían a coinfecciones (48 casos), es decir causadas por más de un germen. La combinación que se pudo observar con más frecuencia fue la de Campylobacter sp. con Aeromonas sp. con 25\% (12/48) y Campylobacter sp. con Shigella sp. con $23 \%$ (11/48). Además, se vio infecciones por tres gérmenes en dos de los casos, Campylobacter, Salmonella y Vibrio cholerae no toxigénico en uno y Campylobacter sp., Salmonella sp. y Plesiomonas shigelloides en otro. Los aislamientos de infecciones mixtas se muestran en la tabla 2.

Como en otras publicaciones, en la mayoría de combinaciones se encontraba presente Campylobacter sp. acompañado de otro germen $(7 \text { de } 11)^{(5,6)}$. 
Tabla 2. Aislamientos en coinfecciones.

\begin{tabular}{|c|c|c|}
\hline Microorganismos & $\mathrm{N}^{0}$ de casos & $\%$ \\
\hline Campylobacter sp. + Aeromonas sp. & 12 & 25,0 \\
\hline Campylobacter sp. + Shigella sp. & 11 & 22,9 \\
\hline Campylobacter sp. + Salmonella sp. & 6 & 12,5 \\
\hline Campylobacter sp. + P. shigelloides & 6 & 12,5 \\
\hline Shigella sp. + Aeromonas sp. & 6 & 12,5 \\
\hline Shigella sp. + P. shigelloides & 2 & 4,2 \\
\hline Yersinia enterocolitica $+P$. shigelloides & 1 & 2,1 \\
\hline Salmonella sp. + Shigella sp. & 1 & 2,1 \\
\hline Campylobacter sp. + V. cholerae & 1 & 2,1 \\
\hline Campylobacter sp. + Salmonella $s p+$ V. cholerae & 1 & 2,1 \\
\hline Campylobacter $s p .+$ Salmonella sp + P. shigelloides & 1 & 2,1 \\
\hline Total & 48 & 100,0 \\
\hline
\end{tabular}

Usualmente, la etiología microbiológica de la diarrea no es obvia clínicamente. Por lo tanto, el diagnóstico de laboratorio adquiere gran importancia, ya que se debe instaurar en el paciente un tratamiento de rehidratación, y dependiendo del agente o los agentes etiológicos y la gravedad del cuadro, implementar terapia antimicrobiana. Pero, hay que tener en cuenta al aumento de la resistencia a los antibióticos en estos últimos años, en especial a quinolonas y betalactámicos, de uso habitual en infecciones gastrointestinales.

\section{REFERENCIAS BIBLIOGRÁFICAS}

1. Bryce J, Boschi-Pinto C, Shibuya K, Black RE, and the WHO Chile Health Epidemiology Reference Group. WHO estimates of the causes of death in children. Lancet. 2005;365:1147-52.

2. Kosek M, Bern C, Guerrant RL. The global burden of diarrhoeal disease, as estimated from studies published between 1992 and 2000. Bull World Health Organ. 2003;81:197- 204.
3. Perales M, Camiña C, Quiñones C. Infección por Campylobacter y Shigella como causa de diarrea aguda acuosa en niños menores de dos años en el distrito de La Victoria, Lima - Perú. Rev peru med exp salud publica. 2002;19(4):186-92.

4. Giugno S, Oderiz S. Etiologia bacteriana de la diarrea aguda en pacientes pediátricos. Acta Bioq Clin Latinoam. 2010;44(1):63-9.

5. Rincón G, Ginestre M, Harris B, Romero S, Martínez $A$. Frecuencia de bacterias enteropatógenas en niños menores de cinco años. Kasmera. 2002;30(1):33-41.

6. Levya A, Salazara J, Mataa M, Sandreaa L, Paza A, Valeroa K, et al. Bacterias enteropatógenas en la comunidad étnica añu de la Laguna de Sinamaica, estado Zulia, Venezuela. Rev Soc Venezolana Microbiol. 2009;29:84-90.

Carta al Editor recibida el 17 de agosto de 2015.

Contribuciones de autoría:

EGE ha participado en la idea de la investigación, concepción del artículo, la recolección de datos, material de estudio y redacción del artículo.

Fuentes de financiamiento: Autofinanciada.

Conflictos de interés: El autor declara no tener conflicto de interés.

\section{Correspondencia:}

Edgar Gonzales Escalante, Dirección: Av. Brasil 600, Lima 05, Perú. Teléfono: (511) 330-0066 anexo 3201 Correo electrónico: egones_5@hotmail.com 